\title{
Research and Practice of Mixed Teaching in the Course of Electrical Engineering and Electronics
}

\author{
Yan Zhi, Guihua Yang \\ College of Mechanical and Control Engineering, Guilin University of Technology, Guilin, China \\ Email: 56582650@qq.com
}

How to cite this paper: Zhi, Y. and Yang, G.H. (2019) Research and Practice of Mixed Teaching in the Course of Electrical Engineering and Electronics. Open Access Library Journal, 6: e5890.

https://doi.org/10.4236/oalib.1105890

Received: October 30, 2019

Accepted: November 10, 2019

Published: November 13, 2019

Copyright $\odot 2019$ by author(s) and Open Access Library Inc.

This work is licensed under the Creative Commons Attribution International License (CC BY 4.0).

http://creativecommons.org/licenses/by/4.0/

\section{(c) (i) Open Access}

\begin{abstract}
This paper studies how to implement hybrid teaching research and practice in the course of "Electrical and Electronic", explores the mixed teaching mode, method and content suitable for the course of "Electrical and Electronic", and completes the mixed teaching design, the preparation of teaching content, and the teaching video. The recording, etc., establishes the "Electrical and Electronic" course of "time teaching, multiple learning, repeated learning, interactive communication and resource sharing", establishes a hybrid teaching network platform for integrated management and service of mobile teaching, and promotes and applies it throughout the school.
\end{abstract}

\section{Subject Areas}

Education

\section{Keywords}

Electrical and Electronic, Hybrid Teaching, Teaching Reform

\section{The Realistic Background and Research Significance}

"Electric and Electronic" is a basic course of science and engineering. The traditional "Electrical and Electronic" course teaching mode is mainly based on theoretical teaching and combined with the laboratory as the platform to carry out teaching. The teaching process is mainly the teacher explanation and student operation, but teachers, school hours, experimental conditions and differences in student learning foundations have led to some college students with less hands-on experimentation, lack of learning initiative, and lack of interest in learning, therefore, reforming the traditional "Electrical and Electronic" course 
teaching is very necessary [1].

In recent years, the use of computer systems, Internet technology, mobile terminals to carry out online learning, such as rain classrooms, MOOCs, micro-courses, flip classrooms, etc., has a profound impact on the traditional classroom teaching model. These new teaching modes are explored and applied in the teaching of the curriculum, which has important epochal significance and practical value for promoting the reform of college teaching., but the experimental courses cannot copy the existing online course teaching mode, how to introduce information technology in the "Electrical and Electronic" course, and improve students' interest in experimentation and the open sharing of learning resources are issues that teaching workers must think deeply about and study [2].

\section{The Design of Mixed Teaching}

Hybrid learning consists of five elements: real-time learning, custom pace learning, collaboration, assessment, and learning aids. Mixed learning is not only a mix of learning styles, but also a mix of teaching elements, including teaching methods, teaching models, teaching resources, the teaching environment, teaching medium, teaching objectives and other elements, in order to get the maximum return with the minimum investment. "Micro-courses", "overturning classes" and "Mu classes" are important carriers and learning methods for mixed learning.

At present, the research of mixed learning mainly focuses on the design and application categories. Among them, the most active ones are theoretical foundation, teaching design and practical application [3]. The application of mixed learning in school education, from the current situation of platform and resource research, the practical application of schools based on various network platforms is the development trend of mixed learning research. There is still little research on the implementation of the hybrid teaching model in "Electric and Electronic", and the research is relatively weak, so further research and practice are needed. This research will build a new hybrid teaching mode of "e-learning + classroom teaching + experimental operation" to realize the "Electrical and Electronic" course mobile teaching integration of teachers and students "every time teaching, multiple learning, repeated learning, interactive communication and resource sharing" Management and services.

Combined with the characteristics of higher education teaching, the information technology is introduced into the curriculum teaching, which realizes the effective integration and seamless integration of the traditional offline teaching methods and the Internet online teaching methods, realizing real-time online interactive communication and resource sharing between teachers and students. Learning is becoming more and more informational and networked. The new teaching method shifts from "teacher-centered" to "student-centered" [4]. The emergence of a mixed learning teaching model characterized by "face-to-face 
teaching and the integration of different types of technical media" will be widely used in higher education. Therefore, a new hybrid teaching model of "e-learning + classroom teaching + experimental operation" is constructed.

"Mixed" is a key issue in mixed learning. There is no uniform standard for how to "mix", which brings us more practice and exploration space. Teachers try to integrate the effective "teaching" in the class with the "learning" of students' extracurricular autonomy, and the curriculum resources are "micro-courses". The short and precise micro-video meets the psychological characteristics of the learners, and it can not only be compared with the actual classroom experiment. Together, it can also be used for independent and in-class study. The teacher uses virtual simulation experiment as an auxiliary tool for digital-analog electric experiment teaching. The virtual simulation experiment is also part of the mixed learning [5]. The virtual simulation experiment can also repair the fault of some knowledge, realize the virtual and real combination of the teaching process, and make the experiment out of time, place, Trouble with device limitations.

Therefore, reforming the traditional "Electrical and Electronic" teaching mode and constructing a new hybrid teaching model of "e-learning + classroom teaching + experimental operation" can effectively compensate for the "fault" problem between teachers and students and achieve a win-win situation.

To conduct research and practice of mixed teaching in the course of "Electric and Electronic", explore the mixed teaching mode, method and content suitable for the course of "Electrical and Electronic", complete the mixed teaching design of the course, the compilation of teaching content, the recording of teaching videos, etc. Establish an "Electrical and Electronic" course of "Teaching at Any Time, Repeating Learning, Repeating Learning, Interactive Communication and Resource Sharing", and constructing a new hybrid teaching model of "Internet Learning + Classroom Teaching + Experimental Operation" to establish an integrated management of mobile teaching and The service of the mixed teaching network platform, and the promotion and application in the whole school is of great significance.

Practice as the sole criterion for testing truth, experimental teaching plays a pivotal strategic position in the cultivation of talents. Digital-analog power is an experimental-oriented course. Experiments are not only the basis for forming the concept of circuit theory and mastering the basic laws of circuits, but also the key to cultivating students' practical ability and innovative thinking ability. Therefore, the teaching effect of "Electrical and Electronic" courses is innovative. The cultivation of talents is crucial.

Analyze which experimental research in the "Electrical and Electronic" course is suitable for online learning, which needs offline teaching; which is suitable for virtual simulation experiments; which is suitable for combination of virtual and real experiments; clear what content teachers need to prepare online and offline, and in-depth guidance Students learn effectively. Organize the corresponding teaching materials, including the selection and arrangement of teaching content, the pro- 
duction of micro-video, the preparation of simulation experiments, the setting of mixed teaching problems, the control table of mixed teaching process, and the link of learning materials. Produce all the texts, pictures, electronic lesson plans, teaching videos and other digital resources needed for the corresponding experimental research, and form a comprehensive, multi-angle, three-dimensional "Electrical and Electronic" hybrid teaching platform resources.

\section{The Practice of "Electrical and Electronic" Mixed Teaching Reform}

In the 2018 students of the school, the practice of "Electrical and Electronic" mixed teaching reform was carried out. Two majors were selected to conduct the teaching pilot according to the mixed teaching mode. In the teaching process, the teaching effects were compared according to the mixed teaching evaluation model. Continuously summarize the results of mixed teaching and improve the teaching platform of mixed teaching. On the basis of the total and promotion application of the "Electrical and Electronic" mixed teaching mode, we will further improve and summarize the mixed teaching mode and mixed teaching materials, promote and apply it in the whole school of science and engineering, and actively communicate and promote the application with other universities. In this study, the teaching model of "Electrical and Electronic" was reformed based on the improvement of practical ability, and the transformation from teaching to learning was mainly carried out; the combination of in-class and in-class integration was emphasized; emphasis was placed on extracurricular learning and self-help. Learning, the result assessment is a combination of results and process control; emphasizing the combination of curriculum theory, practice, and application, to achieve the following reform goals.

\section{The Scope of Implementation and Beneficiary Students}

It is planned to carry out pilot projects in the automation and mechanical control of the school. After maturity, it will be used throughout the school and benefit more than 500 students each year. In addition, the promotion and application in Guangxi universities will further expand the benefits. This teaching reform changes a single learning mode based on classroom teaching, embodying the "student-centered" teaching philosophy. Students can independently and voluntarily learn to watch experimental course videos, courseware, auxiliary materials, etc., learn the enthusiasm of the experiment, and realize the ideals of on-demand learning, efficient learning and happy learning for college students.

\section{Acknowledgements}

This paper is supported by Guangxi Education Science "Thirteenth Five-Year Plan" Project "Building and Application of the Creation Education Ecosystem in Guangxi University of Science and Technology" (2017C377). 


\section{Conflicts of Interest}

The authors declare no conflicts of interest regarding the publication of this paper.

\section{References}

[1] Wang, J.M. and Yuan, W. (2016) Mixed Teaching of MOOC: Theory, Form, Goal. Heilongjiang Education, Theory and Practice, 12, 12-15.

[2] Tian, X. (2016) Research on the Status Quo of Mixed Learning Research and Application Countermeasures. Education Modernization, No. 22, 211-212.

[3] Guo, D. (2011) Research on the Effectiveness of Mixed Learning. Chinese Adult Education, No. 7, 153-156.

[4] Yu, X. and Zhang, W.L. (2011) Research Status and Trend Analysis of Mixed Learning. Modern Educational Technology, 7, 14-18.

[5] Xiao, W. and Zhang, S.Y. (2016) Frontiers, Hotspots and Trends in the Field of Mixed Learning Research. Electro-Educational Research, No. 7, 27-33. 